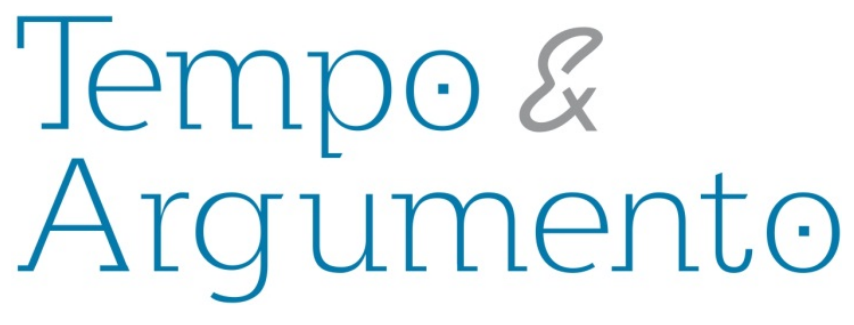

\title{
Desequilíbrio de histórias parte I: um problema do campo das humanidades (?)
}

\section{Resumo}

No presente artigo, discuto alguns desdobramentos de um problema relevante no tempo presente e que integra (ou deveria integrar) a essência do ofício do historiador e de cientistas do social de forma geral. É o que venho chamando de desequilíbrio de histórias. Serão analisados alguns dos desafios que precisam ser enfrentados, referentes à produção e à circulação de histórias. O intuito é instigar o debate em torno dos compromissos da história, do historiador e das ciências humanas no combate ao desequilíbrio de histórias, explorando a intersecção entre a produção acadêmica e o mercado de produção de conteúdo. Num segundo texto, que dará continuidade a este, apresentarei algumas possibilidades de atuação diante do referido problema para além da academia, explorando as ações de uma iniciativa multidisciplinar da qual faço parte: a Retrato Ateliê de Narrativas Multimídia.

Palavras-chave: Mercado. Academia. Desequilíbrio.

História. Histórias.

\author{
Marcelo Róbson Téo \\ Doutor em História Social pela \\ Universidade de São Paulo (USP). \\ Pesquisador colaborador junto ao \\ Programa de Pós-Graduação em História da \\ Universidade de Campinas (UNICAMP). \\ Florianópolis - Santa Catarina - BRASIL \\ marceloteo@hotmail.com
}

Para citar este artigo:

TÉO, Marcelo. Desequilíbrio de histórias parte I: um problema do campo das humanidades (?).

Tempo e Argumento, Florianópolis, v. 10, n. 23, p. 358 - 380, jan./mar. 2018. 


\title{
Imbalance of histories part I: a problem of the field of humanities (?)
}

\begin{abstract}
This article discusses some developments of a relevant problem in the present time that integrate (or should integrate) the essence of the office of the historian and social scientists in general. It's what I've been calling a unbalance of stories. Some of the challenges that need to be addressed regarding the production and circulation of stories will be analyzed. The aim is to instigate the debate around the commitments of history, the historian and the human sciences in combating the unbalance of stories, exploring the intersection between academic production and the content production market. In a second text, which will give continuity to this, I will present some possibilities of work beyond the academy facing the aforementioned problem, exploring the actions of a multidisciplinary initiative of which I am a part of: the Retrato Multimedia Narrative Atelier.
\end{abstract}

Keywords: Market. Academy. Unbalance. History. Stories.

Não há novidade em afirmar que vivemos hoje um (ou vários) desequilíbrio(s) narrativo(s). Chimamanda Adichie, conhecida escritora nigeriana, chamou atenção para o “perigo da história única” (ADICHIE, 2009), um outro nome para o desequilíbrio entre as histórias do ocidente branco, heteronormativo, e as histórias de pessoas que, como ela - 
20ob). Ambos os autores compreendem o poder da narrativa, enxergando-a como o primeiro passo para construir um mundo menos desigual. É também a chave para alcançar uma compreensão complexa da alteridade. Para Achebe, citando um antigo provérbio africano, "até que os leões não aprendam a produzir seus próprios historiadores, a história da caça continuará glorificando o caçador". O relato chama a atenção para o fato de apenas o caçador escrever as histórias de seus encontros com o leão, tornando-se o herói em todas elas. Os leões, por outro lado, não têm história. E sua força e habilidade na caça não são suficientes para criar um equilíbrio narrativo.

O fato é que, independente do nome que dermos a tal fenômeno, somos todos vítimas, em alguma medida, do desequilíbrio de histórias. Pessoas sofrem com a ausência de narrativas que thes representem e provoquem identificação. Sem instrumentos de empoderamento, encontram dificuldade em sensibilizar o público estrangeiro às suas comunidades para o valor de suas próprias jornadas. Outras sofrem com a carência de histórias diversas. Sem conhecer o outro, tornam-se agressores, mesmo sem desejar sêlo. Com baixa capacidade sensível e baixos níveis de empatia, constroem suas vidas sobre bases frágeis, permeadas por conflitos e violência, apesar de garantir privilégios conquistados através do racismo, do machismo, entre outras formas de exclusão. Muitos de nós estamos nos dois polos, sendo agredidos e sendo agressores, simultaneamente.

Esses conflitos narrativos, presentes ao longo da história e da geografia mundial, tornam-se cada vez mais graves. Apesar da democratização do acesso às ferramentas de produção e circulação de narrativas, sobretudo audiovisuais, novas tecnologias têm sido utilizadas para criar ambientes virtuais cada vez mais fechados e menos diversos, propagando o desequilíbrio narrativo e a invisibilidade social em diversas instâncias de nossa sociedade; entre brancos e negros, homens e mulheres, heterossexuais e outras formas de expressão e identidade sexual, entre “cidadãos" e imigrantes, entre ocidente e oriente, entre países ricos e subdesenvolvidos, entre a grande mídia tradicional e mídias 
comunitárias, entre o poder público e o poder comunitário, entre o mercado e outras instâncias da sociedade, como a academia, por exemplo.

Histórias são produzidas diariamente aos milhares, respondendo a demandas diversas. A maioria absoluta delas ignora necessidade de inclusão e diversidade na escolha de seus personagens, alimentando uma complexa cadeia geradora do desequilíbrio de histórias. Tudo isso agravado pelo uso de algoritmos na curadoria involuntária de conteúdos que nos é imposta na maioria das plataformas que acessamos diariamente, bem como no controle da circulação de informações praticado por grandes veículos e plataformas como o Facebook, em que o alcance é definido em grande medida pelo valor do impulsionamento.

É um problema complexo, que envolve diversas variáveis (uso de tecnologias, demanda, oferta e consumo de histórias) e sujeitos (produtores, consumidores, personagens). Acredito que a academia, em especial o campo das ciências humanas, pode e deve integrar esse movimento de transformação rumo a um consumo de histórias mais diverso e inclusivo. Apresento, neste artigo, alguns desafios que batem à nossa porta e, a meu ver, devem ser enfrentados, referentes à produção e à circulação do conhecimento histórico, ou, ainda melhor, à produção e circulação de histórias. Tanto a escolha das variáveis quanto o olhar lançado a elas é ainda bastante experimental e nada ortodoxo, propondo diálogos com campos distantes do universo intelectual tradicionalmente aceito nas humanidades. O intuito é instigar o debate em torno dos compromissos da história, do historiador e das ciências humanas como um todo com a formulação de soluções possíveis no combate ao desequilíbrio de histórias, explorando a intersecção entre a produção acadêmica e o mercado do ponto de vista metodológico, ainda que em sua superfície. Num segundo artigo (TÉO, 2018), exploro algumas propostas concretas de ação que estão sendo elaboradas junto ao Retrato Ateliê de Narrativas Multimídia, iniciativa multidisciplinar da qual faço parte, ilustrando algumas das possibilidades de atuação do historiador/cientista social junto ao mercado de produção de conteúdo. 


\section{A imagem e o futuro do presente}

Um dos grandes desafios do historiador - e das ciências humanas como um todo na atualidade é a construção de uma narrativa mais inclusiva no que diz respeito às linguagens e à sua recepção fora dos muros da universidade. Uma história para além do papel, que encare a questão da representatividade para além da teoria, trazendo os sujeitos estudados para dentro do espectro de consumidores de conteúdo produzido pela academia, reconhecendo-os também como produtores de conhecimento e, ainda, se integrando às transformações do mundo de forma mais ágil.

Nós, historiadores, somos ávidos consumidores do passado. Recentemente, temos nos preocupado com a aproximação rumo ao tempo presente, como forma de interagirmos com ele, transformando-o à medida que o colocamos em perspectiva, que o exploramos enquanto cruzamento de temporalidades ou consequência do passado. Acredito que seja a hora de darmos mais um passo à frente e olharmos para o futuro próximo. Não em termos semânticos, mas na literalidade mais pura da expressão. Qual é o lugar reservado para a história nas próximas décadas? Qual é o espaço disponível e o impacto real das narrativas históricas produzidas pela academia? Ao elaborar estas perguntas, não estou pensando apenas nas reformas curriculares ou na onda conservadora que assola o país, mas, sobretudo, nas condicionantes tecnológicas que batem à nossa porta e na transformação dos hábitos de consumo de conteúdo da população em geral.

A internet das coisas, a inteligência artificial, o blockchain, a popularização da impressão 3D, a realidade combinada, as nanotecnologias, a robótica e a transhumanidade já estão em estágios de implementação avançados. Os novos futuristas (termo utilizado hoje para nomear estudiosos e desenvolvedores de tendências em tecnologia) apontam para a inevitabilidade destas revoluções, que causarão mudanças radicais no comportamento humano e nas formas de consumo de conteúdo. Nos cabe, ainda, o importante papel de discutir seus rumos, sua ética, suas implicações, sobretudo entre comunidades fragilizadas pela falta de acesso a aparatos tecnológicos. 
Até 2020 , a previsão é de que cerca de $75 \%$ do tráfego móvel on line será para consumo de vídeos. O acesso gerado pelas plataformas de compartilhamento de conteúdo audiovisual (Facebook, Youtube, Vimeo, Instagram etc.) tem feito crescer a utilização do vídeo entre cientistas sociais e estudantes, permitindo o aparecimento de “celebridades do conhecimento”, como Clóvis de Barros Filho ou Leandro Karnal. Apesar dos escorregões, estas figuras têm levado a reflexão filosófica e histórica a um mar de pessoas nunca antes navegado - pelo menos no caso brasileiro.

Aprendemos nas últimas décadas que as imagens e sons carregam especificidades em relação ao texto, exploradas quase que somente do ponto de vista documental. São poucos os estudos, advindos em sua maioria do campo da história pública e da antropologia visual, que trabalham com a linguagem audiovisual como parte da construção narrativa nas ciências humanas. E a grande dificuldade destes trabalhos, a meu ver, é a permanência das lógicas da textualidade, não apenas no que diz respeito à linguagem, mas, sobretudo, às suas formas de circulação. Além do foco nos usos historiográficos da imagem, na sua potência comunicadora e nas dinâmicas singulares que envolvem a sua produção, organização e circulação, é preciso que se tenha em conta o universo tecnológico e midiático do mundo contemporâneo, no qual a visualidade desempenha papel de destaque.

Todos conduzimos parte de nossas vidas sob a forma de imagens. As múltiplas virtualidades das novas tecnologias e do ciberespaço abrem lugar para novas narrativas e habilidades inéditas. Cada vez mais nos acostumamos a pensar e nos comunicar de forma imagética, pictural, diagramática. E a alfabetização destes novos leitores de imagens tem sido feita, em maior medida, via publicidade, cinema e jornalismo, áreas da comunicação nas quais são formados ótimos produtores (no sentido técnico) de narrativas (áudio)visuais, mas a quem falta, muitas vezes, poder de análise do social, habilidade tão comum entre historiadores e cientistas sociais. Isso é visível no perfil de grande parte das novas celebridades da internet - youtubers, blogueiros, influenciadores digitais em geral. Carentes de conteúdo relevante, são hábeis entertainers, multiplicando seguidores aos milhões com um humor pautado em jump cuts e auto-exposição, além, é claro, de uma 
capacidade brilhante de pinçar temas da atualidade que despertem a atenção de multidões nunca antes mobilizadas ${ }^{1}$.

A reflexão sobre os papéis da imagem (e dos sons) na narrativa histórica deve, portanto, extrapolar os impasses teóricos advindos da era dos documentos visuais. Eles continuam relevantes. Mas é preciso refletir sobre os destinos possíveis da imagem, sobre as formas de disseminá-la e, antes disso, as exigências de uma narrativa visual: a presença do autor, as licenças ficcionais, a necessidade de diálogo com o espectador, o trabalho necessariamente coletivo, as exigências e possibilidades na distribuição, entre outras. As histórias, por mais diversas e imprevisíveis que sejam, possuem demandas internas parecidas, tanto na sua produção quanto na sua forma de contar. Na lógica da pesquisa acadêmica, a estrutura não está voltada para a evolução de uma história - o storytelling -, mas para estruturação metodológica do objeto. Por isso parece complicado aceitar um molde universal, como o da jornada do herói de Joseph Campbell (1995), dentro do qual cabem mitos, histórias, filmes, romances, contos e lendas. Mas a verdade é que a transformação e a repetição nem sempre são opostos. Como na música, a melodia (objeto de pesquisa), ainda que se sobreponha ao ritmo (forma, repetição), não alcança sentido algum sem ele, perdendo a sua essência. O conhecimento também precisa de ritmo. Pelo menos em sua apresentação final. A circulação intra-acadêmica é um ensaio. Nele surgem as ideias brilhantes, os grandes intérpretes, o prazer cotidiano da arte. Não há arte nem palco sem ensaio. Não há conhecimento sem autonomia na academia. Mas é no palco que realizamos nossas fantasias. A transformação social que motiva muitos de nós pode ser alcançada quando nossas melodias (as pesquisas), sustentadas por uma ritmada narrativa, alcançarem o público a que se destinam, provocando-lhes identificação. Esta última é criada, sobretudo, por este "ritmo do conhecimento", ou seja, pela estrutura da história e por suas células rítmico-culturais, fazendo com que a audiência sensível se sinta ao mesmo tempo valorizada em sua cultura e habilidosa em sua capacidade de ler e compreender.

\footnotetext{
${ }^{1} \mathrm{O}$ caso do youtuber Whindersson Nunes é exemplar. Hoje, com 22 anos - mas atuando desde os 15 -, seu canal conta com mais de 24 milhões de inscritos, o maior do Brasil e o $20^{\circ}$ do mundo. A soma de visualizações de seu canal já passa de dois bilhões. Em pesquisa realizada em junho de 2016 pela Snack Intelligence, divisão da rede Snack de canais no Youtube que monitora e analisa o mercado audiovisual digital, Whindersson foi considerado o segundo youtuber mais influente do mundo.
} 
Estas são questões práticas que ainda não têm despertado um interesse profundo no campo da história, mas que podem definir o futuro da disciplina. A história pública e o ensino de história talvez sejam os caminhos com maior potencial para explorar estas novas possiblidades, mas é importante que tenhamos em mente: disciplinas de mídia e linguagens não são suficientes sem um olhar institucional voltado para o futuro, com pesquisas de tendência e núcleos integrados de desenvolvimento de conteúdo e de tecnologias de acesso. Ampliar os formatos da narrativa histórica é só consequência de um cenário com novos comportamentos e hábitos de consumo de conteúdo. Nos próximos anos, previsões indicam as histórias como o principal canal de acesso à alteridade, tendo em vista o agravamento das práticas de relacionamento virtuais, o que reafirma a importância da História, do historiador e de contadores de história na construção de um mundo menos desigual e mais empático. Neste cenário, nossa relação com a imagem é pautada mais pelo presente (o consumo) e pelo futuro (ferramentas tecnológicas) do que pelo passado. Isso amplia o foco do nosso olhar sobre as imagens: para além das metodologias centradas no documento visual, rumo aos mecanismos de consumo, circulação e gestão de histórias que envolvem a visualidade.

A viabilidade desse processo está condicionada ao nosso compromisso com problemas reais - a invisibilidade social, o desequilíbrio de histórias, entre outros - e não com a solução - a aparência do conhecimento. Gosto de pensar nossos centros (institutos, faculdades, departamentos) como agências públicas de conteúdo. Temos linhas de fábrica produzindo conhecimento bruto, mas somos perfeitamente capazes de assumir a responsabilidade de construir soluções e campanhas para problemas sociais de grande porte. O economista norte-americano Jeffrey Sachs, professor da Columbia University, ao discutir o papel da universidade na resolução de problemas da contemporaneidade, afirma que elas são o lugar ideal para fazer esse progresso. "O problema é que geralmente as universidades não são organizadas por problemas sociais, mas por disciplinas. Isso é bom, pois parte do sucesso das universidades se baseia nessa divisão, mas também é preciso que pessoas de diferentes áreas trabalhem juntas em equipes multidisciplinares" (SACHS, 2017). O grande desafio está em: 1. oferecer as ferramentas certas aos alunos, envolvendo-os não apenas em aulas, mas na solução de 
problemas complexos; 2 . conquistar o apoio institucional necessário para que integremos o mercado de produção de conteúdo, seja fornecendo profissionais críticos, seja produzindo narrativas de divulgação científica; e 3. firmar parcerias transdisciplinares colaborativas para que a formação de novos cientistas do social e a produção de “histórias necessárias" encontre respaldo fora da academia. Não acredito que seja necessário derrubar a universidade e criar outra para isso. A estrutura existe. Basta reorganizá-la, criando novas articulações.

\section{O conhecimento-âncora e as asas da história}

Quando pensamos em divulgação científica, em história pública, quais são as figuras exemplares que nos vêm à mente? Leandro Karnal e Clovis de Barros Filho através do Youtube? A produção editorial de divulgação de figuras como Lilia M. Schwartz e Mary Del Priore? Ou a curadoria crítica feita pelo Café História? Qual o objetivo da histórica pública e da divulgação científica? Mastigar a reflexão acadêmica para facilitar a digestão do grande público? Ampliar o acesso simplesmente? Estimular debates públicos a partir das diretrizes da produção científica? Ou o contrário: usar a ciência do social para compreender e suprir demandas do mundo social? Acredito que todos oferecem valiosas contribuições. Entretanto, precisamos compreender quais são as necessidades e problemas identificados na realidade social, para, só então, na condição de cientistas do social, validarmos soluções.

Entender o que significa - ou o que pode significar - "tornar público" no campo das ciências humanas pode ajudar. Renata Shittino, ao discutir o conceito de público, chama de "via moderna" a perspectiva focada na divulgação do conhecimento (SHITTINO, 2016, p. 45). Nela, o vídeo e as tecnologias de compartilhamento desempenham papéis instrumentais. Permanece uma lógica textual unilateral de transmissão do conhecimento. Um outro caminho apontado pela autora, inspirado por Hannah Arendt, é o do público como compartilhamento, como mundo comum. Neste viés, a ciência histórica aparece como uma forma de abordagem da experiência da 
O ato de compartilhar tornou-se símbolo da cultura contemporânea no que diz respeito à circulação de informações. Somos definidos pelo conteúdo que compartilhamos e pela relevância do que decidimos tornar público. Ser um influenciador digital tornou-se uma valiosa habilidade, tanto no que diz respeito à sociabilidade quanto nos quesitos profissional e político. No âmbito da academia, compartilhar ainda é um termo carente de significação, tendo em vista que a produção de conhecimento, mesmo que gerada por demandas sociais - combate ao racismo, aceitação da diversidade, historicização das diferenças etc. -, se dá de forma endógena, sem priorizar o diálogo com os públicos externos de cada empreitada de pesquisa. Uma tese cujo objetivo geral é combater o racismo, e que o faz através de uma narrativa da história dos mecanismos de segregação racial, pode, depois de atender às demandas de avaliação entre pares na academia, ser destinada ao empoderamento de uma determinada comunidade. Também pode gerar peças de conteúdo voltadas à conscientização do problema entre populações brancas, por exemplo. Cada um desses caminhos leva a produtos completamente distintos, cuja elaboração poderia envolver novas pesquisas sobre o público-alvo e seu consumo de conteúdo, para então criar artifícios de linguagem e distribuição coerentes com a necessidade de cada situação específica. Tais práticas exigem diálogos acadêmicos através de projetos de pesquisa realmente transdisciplinares, além de novas formas de avaliação da produtividade.

Sabemos que, no âmbito das ciências humanas, o conhecimento acadêmico segue um fluxo de produção pautado pela relativa autonomia em relação ao mercado. A independência é uma forma eficiente de garantir, desde a formação mais básica, escolar, que o conhecimento desfrute da qualidade íntegra e confiável de intérprete da realidade social, ao qual devemos recorrer em situações de demanda. No mercado de conteúdo, esta relação é inversa. Priorizam-se as tecnologias de circulação de informação em detrimento do conhecimento, tendo como foco alcançar o maior número de pessoas possível, estimulando algum tipo de consumo, seja de produtos físicos, conteúdos ou ideologias. O resultado é a proliferação de peças superficiais, de relevância bastante 
limitada, sem preocupação profunda com inclusão ou diversidade, com o privilégio de motivações mercadológicas sobre a qualidade e a função social da informação.

Apesar das nuances que suavizam esta dicotomia - tendência de inovadores sociais no campo da comunicação preocupados em transformar o mercado, demandas sociais de grupos como o movimento negro e as mulheres feministas, exigindo e conquistando novas posturas no marketing de grandes marcas - permanece uma oposição entre o conhecimento acadêmico e o conteúdo, supostamente prostituído pela “preocupação mundana” com a circulação de grande porte; uma oposição que alegoriza outra ainda mais radical entre ciências humanas e mercado. De um lado, temos a estrutura universitária das humanidades, que forma milhares de hábeis analistas do social. Criadores de conteúdo, em potencial, são educados para permanecer à margem do mercado, como pensadores críticos que produzem conhecimento, algo que pode ser definido, do ponto de vista da distribuição e do compartilhamento, como uma bela e inspiradora estátua instalada no fundo de um rio de águas turvas. De outro lado, temos uma máquina de histórias guiadas pela ideologia do consumismo. Peças publicitárias, novelas, filmes, imagens destinadas a estimular o consumo de bens e serviços. Ainda que a ênfase em temas ligados à diversidade venha crescendo no campo da publicidade, que vem sendo renovado pela decadência do anúncio tradicional de produtos e pelas demandas sociais em prol da inclusão, o diálogo com a academia é praticamente inexistente.

Muitas agências têm incorporado antropólogos, sociólogos e mesmo historiadores em seus quadros, em busca de aproveitar suas habilidades de análise social na descoberta de tendências. A grande virada do Netflix, por exemplo, se deu a partir dos insights do antropólogo Grant McCracken, que percebeu que o público-alvo da plataforma praticava com frequência as maratonas de séries e programas - binge-watch, em inglês -, passando horas a fio em frente à TV ou ao computador assistindo a um mesmo show ou seriado. A empresa redefiniu a experiência do usuário na plataforma encorajando o binge-watch, e oferecendo temporadas inteiras de uma só vez. Isso mudou a forma de consumirmos séries. McCracken tem advogado em prol da presença de especialistas em cultura na gestão e tomada de decisão no interior das empresas. Segundo o autor, só habilidosos 

apresentar um discurso excessivamente submisso às lógicas do mercado - talvez por não encontrar respaldo em seu campo de origem, talvez por oportunismo editorial -, McCracken consegue descrever de forma inteligente o papel destes analistas da cultura no interior de grandes empresas. Contudo, o faz para um público interessado no campo dos negócios, sem apontar para a formação em humanas como um diferencial. O que é compreensível, tendo em vista nossa completa ignorância no que diz respeito ao campo do empreendedorismo. É preciso trazer essa possibilidade para o interior de nossos núcleos de formação (graduação e pós-graduação), incentivando a participação de cientistas sociais também em posições de decisão - e não apenas de produção - junto ao mercado de conteúdo.

Outra possibilidade interessante é a presença de cientistas sociais na construção do que a etnógrafa de tecnologias Tricia Wang (2016) chamou de thick data, um complemento ao big data - montanhas de dados que têm guiado o desenvolvimento de produtos e ações de marketing de empresas de grande e médio porte. Thick data são dados coletados na realidade social, no contato com pessoas, na prática cotidiana das tecnologias, ou seja, da mesma forma que nós, cientistas do social, encontramos a matéria-prima para nossas pesquisas. Uma habilidade complexa e muito bem desenvolvida nos atuais currículos de graduação, e que vem sendo muito bem explorada por Wang em sua atuação junto a diversas empresas de grande porte, identificando e antecipando tendências no campo da tecnologia a partir do contato direto com pessoas comuns, ou seja, no exercício de uma etnografia voltada ao desenvolvimento de produtos.

Mas ainda não há caminhos que apontem para um mercado preocupado em integrar o conhecimento acadêmico e reformar seu sistema de valores. Estes exemplos apontam para a exploração do potencial exclusivamente mercadológico das técnicas de pesquisa das ciências humanas. Enquanto isso, no outro polo, ocupamos a posição importante, embora pouco eficaz - de crítica vigilante do conteúdo produzido pelo e para 
o mercado, detectando a fragilidade de seus conceitos e os problemas decorrentes do seu consumo. Praticamente toda a produção acadêmica nas ciências humanas é pensada dentro de uma estrutura que inclui a pesquisa, a construção do conhecimento, a crítica intelectual do presente e, numa escala ainda pequena, a oferta de conteúdo para o mercado, via publicações de divulgação, sites, blogs e programas de TV/internet. Sua interação com o mercado de conteúdo é feita sob demanda, sejam elas demandas políticas, temáticas ou editoriais. Diferente, portanto, das agências e produtoras de conteúdo, acostumadas a gerar demandas. Essa distinção, aparentemente tão simples, gera um descompasso imenso entre as questões sociais que movem o campo das humanidades e as ações dinâmicas do mercado de conteúdo, entre o diagnóstico universitário, que aponta para a importância da diversidade na construção de um mundo menos desigual, e as narrativas sedutoras de estímulo ao consumo.

De um lado, temos trabalhos acadêmicos de excelência que detectam problemas sociais e analisam com destreza suas consequências, mas que não são pensados enquanto produtos, enquanto conteúdo que precisa circular e gerar demandas. De circulação quase insignificante se comparada com qualquer peça publicitária, nossos trabalhos repetem um formato desatualizado de monografias dos oitocentos, interessante apenas àqueles que são educados para suportá-lo². Embora necessária à construção do conhecimento, essa estrutura encontra dificuldades para escoar sua produção para fora dos muros da universidade. As ações de extensão, pouco valorizadas em relação à pesquisa nos sistemas de avaliação produtivista vigentes, dificilmente conseguem engajar comunidades externas de forma ampla e comprometida, porque raramente são pensadas a partir de demandas externas. E quando são, carecem de serviços e conhecimento especializados para criar campanhas e gerir comunidades com eficiência, que utilizem tecnologias e mídias sociais de forma profissional. Práticas como a

\footnotetext{
2 Faltam pesquisas e métricas sobre o público de leitores de artigos acadêmicos no campo das humanidades. Um levantamento recente na área da saúde apontou que cerca de 1,2 milhão de artigos científicos são publicados anualmente. Menos de 10\% são lidos por mais de três pessoas. Os dados, apresentados pelos criadores do aplicativo Mind the Graph, também indicam que artigos com artifícios visuais são mais acessados e lidos. Partindo de tal premissa, o aplicativo auxilia cientistas a lidar com o design visual de seus textos, oferecendo vias pré-moldadas para a elaboração de ícones ilustrativos, infográficos etc. Para maiores informações sobre o aplicativo e o seu funcionamento, acessar: $<$ http://mindthegraph.com>.
} 
definição de público-alvo, a construção de personas e mapas de empatia, tão comuns no universo das campanhas de marketing, são estranhas ao trabalho do historiador/cientista social, mesmo que muitas dessas metodologias tenham inspiração na história e na antropologia. Sem investigar demandas, nossos pesquisadores acabam cometendo um pecado no campo do empreendedorismo: lançar um produto que é fruto de uma paixão pela solução e não pelo problema. O resultado: ótimas ideias, desenvolvidas com profundidade e propriedade, mas que sofrem com a escassez de utilizadores, contribuindo muito pouco para a resolução do problema que lhes deu origem.

No outro polo, narrativas mercadológicas, em grande parte audiovisuais, são produzidas aos milhares, destinadas à grande circulação, à pesca de espectadores, especializadas em detectar nossas expectativas e preenchê-las, criando sonhos de consumo. Cresce, assim, o desequilíbrio entre a reflexão acadêmica e o circuito de histórias produzidas pelo e para o mercado (publicidade, séries de TV, filmes etc.); situação que é agravada ainda mais pelo uso de algoritmos que trabalham para direcionar nosso consumo de conteúdo, criando o que Paul Saffo (2005) chamou de personal medias, ilhas de histórias semelhantes à nossa. ${ }^{3}$

Demandas populares exigem a presença de temas como o respeito à diversidade, aos direitos da mulher, da/o negra/o, dos povos indígenas, das comunidades LGBTQ+, das pessoas com deficiência entre outras/os, entre as narrativas de consumo. A academia, apesar do seu potencial para guiar este processo, não parece estar reagindo ou exigindo sua participação enquanto gerador de conhecimento/conteúdo de grande circulação. Empatia e diversidade são conceitos que têm sido apropriados pelo mercado. Algumas empresas tradicionalmente violentas no trato com a imagem da mulher, por exemplo, como marcas de cerveja, têm criado novas estratégias de marketing que respondem a essas demandas [figura 1]. Criam-se, em muitos casos, versões rasas e parciais dos debates empreendidos na universidade. Mas a permeabilidade do mercado a estes valores tem rendido frutos interessantes. Experiências incríveis de pluralidade, engajamento e conexão com os sujeitos das histórias (mesmo que vistos como

\footnotetext{
${ }^{3}$ Para saber mais sobre o desenvolvimento de algoritmos e sua relação com o que poderíamos chamar de enquistamento ideológico, ver PARISER, 2011.
} 
consumidores), através de um envolvimento imersivo com o problema abordado e de uma pesquisa profunda sobre o destino (público-sensível) de determinada narrativa. Campanhas publicitárias têm gerado debates necessários sobre gênero, sexualidade, preconceito, ao invés de simplesmente anunciar um produto ${ }^{4}$. Atualmente, pode-se dizer que a maior parte das narrativas que nos emocionam e correm o mundo através das redes sociais, carregam consigo intenções mercadológicas, seja no formato de branded content, native advertisement, marketing ou entertainment. Feitas de forma independente com relação à universidade, raramente carregam os aprendizados emanados dela. A academia, por sua vez, vem perdendo seu prestígio progressivamente, sobretudo pela ausência de vozes audíveis no cotidiano das pessoas comuns.
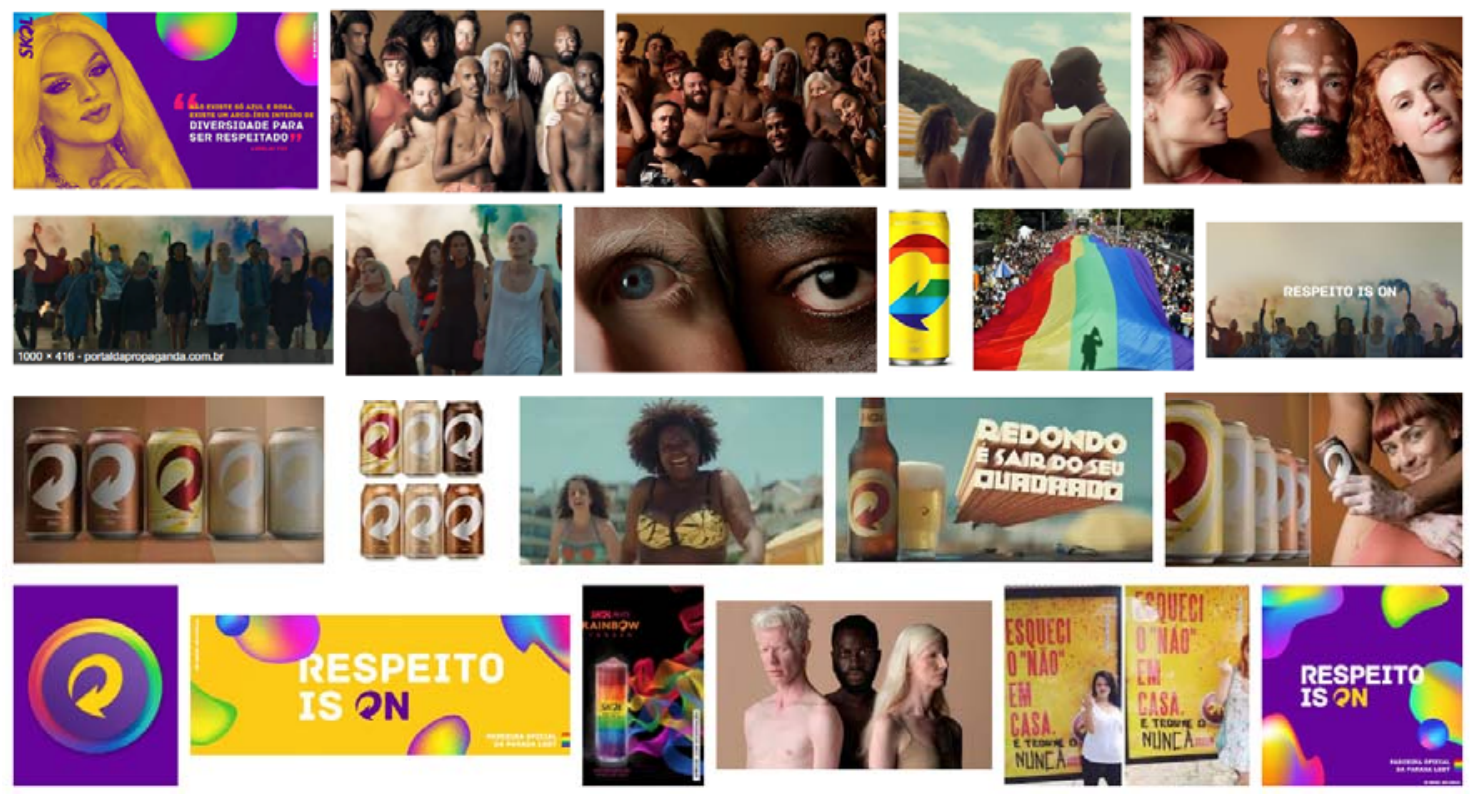

Figura 1. Imagens da nova campanha da marca de cerveja Skol, pautada pelo conceito de diversidade. Junto com as peças publicitárias, a marca tem investido em ações de branded content que contribuam para renovar sua identidade, tentando apagar anos de violência contra a mulher, reforçando estereótipos machistas comuns às campanhas do segmento. Sem levar em conta os avanços na discussão sobre o conceito de diversidade, a campanha repete os clichês de anúncios como o do suco artificial Tang, nos anos 80, associando diversidade à aparência física e à cor da pele.

4 Ver, a título de exemplo, a premiada campanha "Run like a girl", de 2015: $<$ https://www.youtube.com/watch?v=XjJQBjWYDTs $\geq$. 
Esse cenário levanta alguns questionamentos polêmicos, pois afetam o status quo da nossa profissão, atingindo especialmente a zona de conforto de acadêmicos de carreira, cuja distinção se dá via valorização do manto antiquado da erudição ocidental. O saber que emana dela, embora rico em complexidade, aceita a condição de âncora. Imerso em bibliotecas, assegura que seus produtores não sejam levados pelas marés do presente e do futuro, permanecendo, de alguma forma, atados às profundezas do passado. O peso desse conhecimento bruto precisa, em alguma medida, diluir-se em áreas maiores, que lhe permitam navegar e gerar demandas junto à sociedade, aproveitando seu potencial de diagnóstico social para criar soluções de impacto positivo. A transformação das características físicas da matéria "conhecimento" depende de uma série de experimentos e ações que devem transcender, sem ignorar, a preocupação com as leis internas da disciplina. O ingresso da história e das ciências humanas no mercado de produção de conteúdo implica em aderir às regras da competitividade mercadológica, mesmo que com o foco em transformá-las. Como gerar mais impacto ou o impacto necessário? Como atrair a atenção de audiências consideradas relevantes aos problemas enfrentados? Como fortalecer a marca do conhecimento acadêmico junto aos públicos de consumidores de conteúdo que participam, inevitavelmente, da construção da realidade social?

Instituições e eventos destinados a discutir a divulgação científica, como o PCST (Public Comunication of Science and Technology), o ICHST (International Congress of History of Science and Technology), o IFPH (International Federation for Public History) ou, no Brasil, o Simpósio Internacional de História Pública, têm se ocupado, cada um à sua maneira, do assunto. Mas o foco permanece nas formas de "divulgação" de produtos essencialmente acadêmicos, com pouco investimento nas possíveis interações de profissionais do campo das ciências humanas com o mercado. Embora a divulgação científica seja fundamental, não me parece suficiente para que consigamos contribuir de fato na resolução de problemas sociais que atingem parcelas da população negligenciadas ou incompreendidas pelo mercado, devido, sobretudo, à ausência de histórias que as representem. A presença da universidade e, em especial, das ciências humanas na gestão das cidades, nas relações internacionais, na produção de conteúdo de 
ampla circulação e na construção de novas tecnologias de impacto precisa passar por uma reformulação estrutural, incorporando novos atributos à imagem do intelectual/cientista/estudante. Atributos estes que devem ser discutidos em profundidade e em conjunto com áreas dedicadas a alimentar o mercado de conteúdo, considerando suas ferramentas e algumas de suas prioridades, como a ênfase na distribuição dos materiais produzidos, o estudo profundo dos públicos de destino, o cuidado com a apresentação dos produtos etc.

A representatividade das narrativas acadêmicas, questão fundamental nos debates sobre cotas universitárias e no processo de implementação das leis 10.639/2003 e 11.645/2008, referentes à obrigatoriedade do ensino de história e cultura afro-brasileira e indígena nas redes pública e particular precisa ser pensada também do ponto de vista da circulação. Ou seja: quem são os sujeitos que se identificam com as narrativas universitárias? A quem elas se destinam atualmente? Como alcançar os protagonistas de problemas como o racismo, o machismo, a homofobia, levando em conta suas variáveis (práticas de consumo de conteúdo, interesses dos nichos envolvidos, anseios das comunidades em posição de demanda)?

É verdade que a cultura escrita, que serviu durante séculos como passaporte para a história, ainda não representa boa parte de seus objetos-sujeitos, sobretudo por não incluir suas perspectivas e formas de contar. Talvez por isso os Kadiwéu chamaram a escola implantada dentro da aldeia de apiigo (cemitério), onde sua cultura era enterrada (SILVA, 2015, p. 28). A dissonância entre as lógicas do congelamento da cultura via escrita e da instabilidade/dinâmica da oralidade causaram, para dizer o mínimo, desconforto à maioria das populações indígenas no processo de ensino/aprendizado escolar da história. Não por acaso, diversas comunidades indígenas Brasil afora têm buscado no vídeo, na fotografia e em narrativas sonoras formas de registrar sua própria história, até então compartilhada pela via da oralidade. Diferente da textualidade, a linguagem audiovisual trabalha com a presença do corpo e do gesto, elementos essenciais, como aponta a estudiosa da cultura afro-brasileira, Maria Antonieta Antonacci, às formas de contar de culturas orais (2009; 2013). Nesse sentido, o alcance das políticas de ação afirmativa e dos dispositivos legais educacionais como as leis federais 10.639/2003 e 11.645/2008 depende 
desse alargamento das formas narrativas, tanto do ponto de vista do consumo de materiais escolares e universitários, quanto do desenvolvimento de novas habilidades técnicas por parte dos alunos, tornando-os sujeitos ativos no processo de democratização dos saberes e culturas, mas não apenas.

A transição de linguagens não dá conta do problema da representatividade. Seja entre povos indígenas ou comunidades periféricas, jovens ou idosos, o consumo de conteúdo de massa via redes sociais e plataformas de grande circulação é uma realidade. E essa prática não pode ser abolida, pois configura parte essencial de suas formas de sociabilidade. É preciso oferecer mais opções dentro deste mesmo espectro, conscientizando o mercado a partir das oportunidades abertas pelas demandas sociais por mais diversidade. Parte essencial do "sentir-se representado" passa pelo reconhecimento de si nas práticas cotidianas de consumo de conteúdo. Levar em conta estas variáveis é fundamental para que o conhecimento acadêmico deixe sua condição de âncora e crie asas, fundindo-se a tantas outras formas de saber e contribuindo para um maior equilíbrio entre elas.

\section{Toda árvore tem raiz}

Toda história tem raízes. E elas dizem muito sobre como e porque crescem, se desenvolvem e se alimentam os contos de cada civilização. Uma das funções da teoria é justamente ser a raiz, não no sentido da gênese, mas da caracterização e delimitação das formas que se apresentam ao mundo em cima da terra. Quais as funções do historiador/cientista social? Quais as funções do conhecimento histórico? O que o primeiro pode e/ou deve fazer com o segundo? Nossa responsabilidade com os problemas de pesquisa termina quando são avaliadas nossas teses, aceitos nossos artigos e relatórios, elogiadas nossas apresentações entre pares em eventos internacionais? Qual a relevância que queremos ter na formação da cultura e da consciência históricas - tais quais concebidas por Jörn Rüsen (2010) - das comunidades externas à universidade? Além de discutir os pressupostos do conhecimento histórico, seus regimes de verdade e historicidade, as armadilhas e sutilezas da análise social, precisamos incorporar a didática 
da história (entendida como disciplina que estuda a consciência história na sociedade como um todo) à essência do nosso ofício. Mas não uma didática que funcione apenas como diagnóstico da cultura histórica de uma determinada comunidade ou nação. É preciso ajudar a construí-la, de forma que a universidade funcione como um gerador de histórias. Contribuiremos, assim, para uma cultura histórica mais inclusiva e diversa.

Quando falo em gerar histórias, não me refiro ao conhecimento histórico isolado, mas à construção de narrativas que incorporem o saber histórico, cumprindo outro destino: alcançar públicos que precisem delas. Nesse processo, moram inúmeros perigos. Não apenas nas já tão debatidas trilhas da história e da ficção. Mas em territórios ainda mais escorregadios, ligados à gestão da narrativa para fora do mundo acadêmico. Como integrar o mercado à produção de conteúdo sem aprofundar ainda mais a mercantilização do conhecimento? Como evitar que o campo histórico se desmanche num conjunto de reflexos pálidos de várias outras disciplinas (cinema, literatura, jornalismo, publicidade, design etc.) à medida que incorpore algumas de suas práticas? Como manter os compromissos éticos e o interesse dos profissionais da história nas atuais e indispensáveis funções (docência e pesquisa) num cenário profissional transformado, no qual historiadores poderiam atuar como produtores de conteúdo para o mercado?

Para resolver tais impasses, precisamos estar cientes de que a história precisa se adaptar constantemente aos modos de leitura/percepção do mundo no período em que está sendo escrita. O seu fazer precisa ser alterado em acordo com as mudanças nas formas de expressão e consumo. E a abertura da história e das ciências humanas para outros formatos narrativos, como o vídeo em suas inúmeras facetas (vlog, ficção, documentário, documento, registro, propaganda etc.), implica numa discussão mais ampla que aquela iniciada por Hayden White (1988) e Robert Rosenstone (1998), sobre as singularidades da linguagem visual. É preciso responder muitas perguntas que ainda não foram feitas, levando em conta as condicionantes tecnológicas que se apresentam (e se apresentarão, dada a veloz flutuação de novas invenções) e as variáveis envolvidas no processo de circulação em larga escala num momento em que distribuição orgânica (nãopaga) de conteúdos vem sendo progressivamente sabotada. 
A reflexão teórica, nesse contexto específico, precisa centrar-se menos nas especialidades que constituem a disciplina hoje, e mais nos pressupostos éticos que devem permear uma nova formação para novos historiadores num novo regime de consumo de/da história(s). Mais do que manter a árvore da história em pé, a raiz da teoria também precisa ajudar a canalizar sua expansão e amplificar o seu alcance. Sem perder a individualidade, deve crescer para atender as demandas do ecossistema que depende dela.

Nesse sentido, a reflexão, no campo da história, sobre a própria disciplina, seus contornos, atributos e funções precisa incorporar perguntas acerca das formas de circulação do conhecimento, priorizando as ferramentas tecnológicas disponíveis, estudando sua sintaxe, suas formas de desenvolvimento, suas tendências e formas de consumo. E esse não é um processo que pode ser deixado para o final, pois tem implicações em toda a cadeia, desde a formação de professores até a elaboração de peças destinadas a circular no mercado de conteúdo. É preciso levar em conta as transformações nas práticas de consumo de conteúdo, produzindo mais vídeos, utilizando mais imagens, contando mais histórias de indivíduos, camuflando a reflexão teórico-metodológica em ações, dramas e artifícios de linguagem capazes não apenas de informar, mas também de entreter o público. É preciso disseminar novos tópicos metodológicos à formação universitária, criando pontes estratégicas com disciplinas de outros campos, como a comunicação e a administração, por exemplo, pois estas narrativas precisam ser gestadas e geridas de forma comprometida e pragmática. Princípios de marketing, gestão, técnicas de design, noções aprofundadas de mídias sociais, tendências em tecnologia e, sobretudo, metodologias de resolução de problemas complexos [lean (RIES, 2012), design thinking (LIEDTKA, 2015), entre outras]: estes são alguns saberes totalmente estranhos à formação em ciências humanas, mas que permitiriam que nossos alunos ampliassem seu campo profissional, cada vez mais espremido, integrando o mercado de conteúdo de forma ativa, para torná-lo um lugar mais conectado com a produção de saberes do campo das humanidades.

Tudo isso precisa ser feito a partir da ótica do desafio, ou seja, buscando formas possíveis de convivência e interação entre o historiador, a sociedade e o mercado. Como 
já mencionei acima, os perigos são inúmeros. E o caminho mais fácil é fechar a porta e decorá-la com diamantes de conhecimento puro. Mas este último é, na verdade, um instrumento, não um fim. E essa porta é um caminho promissor. Só com a ajuda de “teóricos de profissão”, mentes hábeis na análise e criação de engenharias do conhecimento, será possível encontrarmos, do outro lado, uma versão da ciência histórica que nos provoque identificação, gere aceitação e inspire credibilidade. Ou seja, esse debate precisa ser aprofundado no âmbito teórico para que, na sequência, o levemos a outras instâncias. Ao reformar os pressupostos da disciplina no que diz respeito à sua atuação junto à sociedade, sem excluir o mercado, levando em conta a realidade presente e lidando com a variável do futuro, criaremos as bases para uma ciência da sociedade mais efetiva e inspiradora. Talvez com seu status e privilégios diluídos, mas seguramente mais inspiradora, ajudando a criar histórias mais diversas, inclusivas e esclarecedoras quanto à presença do passado no presente.

\section{Referências}

ACHEBE, Chinua. Home and exile. New York: Oxford University Press, 2000a.

ACHEBE, Chinua. Africa: balancing stories. Fidelio, v.9, n.2-3, Summer-Fall 200ob.

ADICHIE, Chimamanda G. The danger of a single story. TED X Global, julho de 2009. Disponível em:

<https://www.ted.com/talks/chimamanda_adichie_the_danger_of_a_single_story $>$. Último acesso em 26 de julho de 2017.

ANTONACCI, Maria A. Memórias ancoradas em corpos negros. São Paulo: Educ, 2013.

ANTONACCI, Maria A. África/Brasil- corpos, tempos e histórias silenciadas. Tempo e Argumento. Florianópolis, v.1, n.1, p.46- 67, jan./jun., 2009.

CAMPBELL, Joseph. O herói de mil faces. São Paulo: Cultrix: Pensamento, 1995.

LIEDTKA, Jeanne. A magia do design thinking. São Paulo: HSM Editora, 2015. 
MCCRACKEN, Grant. Chief Culture Office: como a cultura pode determinar o sucesso ou o fracasso de uma organização. São Paulo: Aleph, 2011.

PARISER, Eli. The filter bubble: what the internet is hiding from you. New York: Penguin Press, 2011.

RIES, Eric. A startup enxuta: como os empreendedores atuais utilizam a inovação contínua para criar empresas extremamente bem-sucedidas. São Paulo: Editores J., 2012.

ROSENSTONE, Robert. História em imagens, história em palavras: reflexões sobre as possibilidades de plasmar a história em imagens. Revista o Olho da História, n. 5. Salvador, 1998.

RÜSEN, Jörn. Razão histórica: teoria da história: fundamentos da ciência histórica. Brasília: Editora da UNB, 2010.

SACHS, Jeffrey. The age of sustainable development. 2017. Palestra realizada no dia 17 de novembro, no auditório da FAPESP. Disponível em <http://agencia.fapesp.br/jeffrey_sachs_defende_cinco_grandes_transformacoes_liderad as_pelas_universidades/26683/>. Último acesso em 23 de novembro de 2017.

SAFFO, P. Farewell Information, It's the Media Age. In: saffo.com, 2005. Disponível em <http://www.saffo.com/wp-content/uploads/2012/01/essay_farewellinfo.pdf >. Último acesso em 22 de outubro de 2017.

SCHITTINO, Renata. O conceito de público e o compartilhamento da História. In: MAUAD, Ana Maria; ALMEIDA, Juniele Rabelo de; SANTHIAGO, Ricardo. História pública no Brasil: sentidos e itinerários. São Paulo: Letra e Voz, 2016.

SILVA, Giovani J. da. Ensino de História indígena. In: WITTMANN, Luisa T. Ensino d(e) história indígena. Belo Horizonte: Autêntica Editora, 2015, p. 21-46.

TÉO, Marcelo. Desequilíbrio de histórias parte II: uma iniciativa em torno de um problema. Manuscrito (a publicar). 2018.

WANG, Tricia. The human insights missing from big data. 2016. Palestra conferida no TED Cambridge em setembro de 2016. Disponível em

<https://www.ted.com/talks/tricia_wang_the_human_insights_missing_from_big_data>. Último acesso em 23 de novembro de 2017.

WHITE, H. Historiography and historiophoty. American Historical Review, Chicago, v. 93 n.5, p. 1193-1199.Dec., 1988. 
Recebido em 15/12/2017 Aprovado em 28/02/2018

Universidade do Estado de Santa Catarina - UDESC Programa de Pós-Graduação em História - PPGH Revista Tempo e Argumento Volume 10 - Número 23 - Ano 2018 tempoeargumento@gmail.com 